\title{
Leptin therapy in lipodystrophy
}

\author{
D. B. Savage • S. O'Rahilly
}

Received: 2 September 2009 /Accepted: 11 September 2009/Published online: 4 October 2009

(C) Springer-Verlag 2009

Keywords Diabetes · Fatty liver - Insulin resistance ·

Leptin · Lipodystrophy · Triacylglycerol

\begin{abstract}
Although much maligned, fat is an essential organ with important mechanical and metabolic roles. Like many good things in life, too much (obesity) or too little of it (lipodystrophy) is unhealthy, whereas maintaining some reserve capacity (leanness) to buffer and accommodate modern eating habits is ideal. So why do we need some fat?

First, to store surplus energy as triacylglycerol and to buffer meal-related NEFA and triacylglycerol fluxes [1]. Second, to release energy in the form of NEFAs for use by other tissues during prolonged exercise or whilst fasting, and, third, to produce hormones such as leptin, which convey information about nutritional status to the brain and other tissues. In the case of leptin, low levels signal 'starvation' and trigger behavioural responses aimed at finding and eating more food, whereas rising levels reflect adequate energy stores and reduce food intake. Unfortunately, the human brain, possibly as a result of a predominant evolutionary drive to survive famine, is far more receptive to falling than to rising leptin levels. In fact, most obese humans appear to be resistant to high leptin levels. This results in ingestion of excess energy, which is initially accommodated by adipocyte hypertrophy and hyperplasia. However, sustained positive energy balance ultimately induces metabolic stress in adipose tissue
\end{abstract}

D. B. Savage $(\bowtie) \cdot$ S. O'Rahilly

University of Cambridge Metabolic Research Laboratories,

Institute of Metabolic Science,

Level 4, Addenbrooke's Hospital, Box 289,

Cambridge CB2 0QQ, UK

e-mail: dbs23@medschl.cam.ac.uk (including hypoxia, increased reactive oxygen species, mitochondrial stress, endoplasmic reticulum stress), adipocyte death [2] and an inflammatory cell infiltrate [3]. Many believe that this compounds adipose tissue dysfunction and exacerbates 'lipid overflow' to the liver and other tissues, where it initiates a series of signalling events culminating in an insulin-resistant state [4].

Lipodystrophy is a rare disorder characterised by a pathological deficiency of adipose tissue. The fat loss may be partial or generalised and may be inherited or acquired in origin. The metabolic consequences are remarkably similar to those of obesity and include fatty liver, dyslipidaemia (hypertriacylglycerolaemia and low HDL-cholesterol), hypertension in some cases, severe insulin resistance and type 2 diabetes mellitus. Pancreatitis is a common complication of the dyslipidaemia, and long-term complications include those typically associated with type 2 diabetes. Very severe insulin resistance generally results in poor glycaemic control, so complications tend to develop early and are often severe. Fatty liver disease is virtually ubiquitous in patients with lipodystrophy and not infrequently progresses to cirrhosis and, in some cases, hepatocellular carcinoma. The severity of the metabolic sequelae are broadly proportional to the extent of fat loss, a fact borne out by the observation that when lipodystrophy occurs in women (who normally have more fat than men) the adverse metabolic sequelae are frequently more severe than those seen in lipodystrophic men [5]. The importance of regional fat depots is apparent in patients with partial lipodystrophy, in whom weight gain generally fails to replace lost fat depots but instead increases the size of residual fat depots and compounds the metabolic problems. In generalised lipodystrophy the physical absence of adipose tissue storage capacity is compounded by severe leptin deficiency, which induces overwhelming urges to find and 
eat food. This phenomenon is much less dramatic in partial lipodystrophy, where leptin deficiency is relative rather than absolute.

The most obvious way to treat lipodystrophy is to replace the missing fat. Unfortunately, unlike the kidney, liver and other organs for which transplantation is feasible and effective, the adipose organ consists of multiple isolated depots, none of which depends on a readily replaceable blood supply. Nevertheless, fat pads [6] and isolated adipocyte precursors (pre-adipocytes [7]) have been successfully transplanted in mice with generalised lipodystrophy. In both cases, triacylglycerol accumulated in the transplanted tissue/cells, but the dramatic metabolic benefits observed appear, for the most part, to be a consequence of reconstituting an endogenous supply of leptin. An alternative approach is to restore circulating leptin levels by pharmacological means. Following the successful use of injectable leptin in congenital leptindeficient mice (ob/ob) [8] and humans [9], investigators were quick to try leptin replacement in lipodystrophic mice [10]. In 2002, Oral et al. [11] were the first to report on the response of nine patients with lipodystrophy to recombinant human leptin therapy. Twice daily subcutaneous administration of leptin led to dramatic improvements in hypertriacylglycerolaemia, fatty liver and glycaemic control $\left(\mathrm{HbA}_{1 \mathrm{c}}\right)$. Subsequent studies conducted at the National Institutes of Health in Bethesda (MD, USA) by Dr Gorden and colleagues showed that leptin replacement is also useful in patients with partial lipodystrophy, albeit less dramatic in this instance [12]. Others have also shown that leptin replacement appears to be helpful in HIV-related lipodystrophy, which is undoubtedly the most common cause of partial lipodystrophy [13].

In this edition of Diabetologia, Chong et al. report on the sustained efficacy of leptin replacement in 48 patients with lipodystrophy over an 8 year period [14]. They conducted an open-label prospective study of patients with acquired and inherited forms of lipodystrophy caused by mutations in the AGPAT2, BSCL2 (seipin), LMNA and PPARG genes. Consistent with previous results, they observed substantial reductions in triacylglycerol levels (59\% decrease) and $\mathrm{HbA}_{1 \mathrm{c}}$ (from $8.4 \%$ to $6.9 \%$ ) in the group as a whole. The magnitude of the response was, as predicted, greater in those with generalised lipodystrophy than in patients with partial lipodystrophy, and, in general, was inversely proportional to the starting leptin level. Most of the patients they treated had starting leptin levels of $<5 \mu \mathrm{g} / \mathrm{l}$, although they do appear to have used leptin therapy in patients with leptin levels as high as $10 \mu \mathrm{g} / \mathrm{l}$. They also noted decreased proteinuria and, although blood pressure was not studied in detail, no consistent effects on blood pressure were noted in these studies. In almost every case, the benefits of leptin replacement were sustained for as long as therapy was continued. Metabolic relapses were rare and appeared to relate to non-compliance rather than a loss of leptin efficacy.

Leptin was extremely well tolerated, with no frequent adverse effects reported beyond the discomfort of daily subcutaneous injections. To date, the only patients in whom adverse effects have been reported appear to be those with acquired generalised lipodystrophy. Two patients with acquired generalised lipodystrophy and mesangiocapillary glomerulonephritis (one of whom was positive for C3 nephritic factor) experienced significant deteriorations in renal function following the initiation of leptin therapy [15]. It was not possible to definitively conclude that leptin replacement was responsible for the deterioration in renal function in either case. Nevertheless, leptin deficiency is known to be associated with a quiescent immune state, and leptin replacement in patients with leptin deficiency induces significant changes in $\mathrm{T}$ cell responsivity [16]. Patients with acquired lipodystrophy, which is thought to be an autoimmune condition, frequently manifest other autoimmune diseases, so one possible explanation for the observed deterioration in renal disease in the patients discussed above is that leptin replacement exacerbated autoimmune renal disease. The authors also report the development of $\mathrm{T}$ cell lymphoma in two patients with acquired generalised lipodystrophy - here too they were unable to establish or entirely refute a causal link, as $\mathrm{T}$ cell lymphoma has previously been reported in the context of acquired generalised lipodystrophy.

Leptin is currently only available through an expanded access programme sponsored by Amylin (San Diego, CA) in the USA or on a named patient compassionate use basis in some other international centres. In our view, its benefits in generalised lipodystrophy are far superior to any other available therapies, and although the market is small, it ought to receive approval as an orphan drug in the relatively near future. In the case of partial lipodystrophy, leptin replacement appears to be of more modest benefit, but is worth adding to other therapies. It is currently only provided to patients with severe lipodystrophy associated with type 2 diabetes and/or hypertriacylglycerolaemia, but its use ought also to be studied in patients with severe lipodystrophy who have 'prediabetes' (i.e. impaired fasting glucose and/ or impaired glucose tolerance).

What are the other options? Although some research in rodent models suggests that leptin may have beneficial effects on metabolic rate and even peripheral actions, most existing rodent data suggest that the dominant effect is a centrally mediated reduction in food intake [17, 18]; an observation borne out by available human data $[9,19]$. If this is true, then reducing food intake should be effective and, although difficult to implement for the reasons discussed above, anecdotal evidence [20] and our own unpublished experience suggests that this is true. Bariatric 
surgery is clearly the most effective way to reduce energy intake in obese individuals and appears to be similarly effective in lipodystrophy [21]. Outside of these dramatic but effective strategies, the approach should generally follow guidelines for obese type 2 diabetic patients, with the expectation that large doses of insulin are likely to be required and that failure to control food intake, at least to some extent, is likely to mean that almost any other therapies are relatively ineffective.

What of the future? Unfortunately for patients with lipodystrophy, common diseases inevitably attract much greater interest and therapeutic endeavour from Big Pharma, making it more likely that useful therapies will be identified for these. The good news is that anything that reduces energy intake in obese patients is likely to be worth considering in patients with lipodystrophy. Significant progress in understanding the genetic basis of congenital forms of lipodystrophy also offers long-term hopes of identifying novel therapeutic targets.

Duality of interest The authors declare that there is no duality of interest associated with this manuscript.

\section{References}

1. Frayn KN (2002) Adipose tissue as a buffer for daily lipid flux. Diabetologia 45:1201-1210

2. Cinti S, Mitchell G, Barbatelli G et al (2005) Adipocyte death defines macrophage localization and function in adipose tissue of obese mice and humans. J Lipid Res 46:2347-2355

3. Hotamisligil GS (2006) Inflammation and metabolic disorders. Nature 444:860-867

4. Savage DB, Petersen KF, Shulman GI (2007) Disordered lipid metabolism and the pathogenesis of insulin resistance. Physiol Rev 87:507-520

5. Garg A (2000) Gender differences in the prevalence of metabolic complications in familial partial lipodystrophy (Dunnigan variety). J Clin Endocrinol Metab 85:1776-1782

6. Gavrilova O, Marcus-Samuels B, Graham D et al (2000) Surgical implantation of adipose tissue reverses diabetes in lipoatrophic mice. J Clin Invest 105:271-278
7. Rodeheffer MS, Birsoy K, Friedman JM (2008) Identification of white adipocyte progenitor cells in vivo. Cell 135:240-249

8. Pelleymounter MA, Cullen MJ, Baker MB et al (1995) Effects of the obese gene product on body weight regulation in ob/ob mice. Science 269:540-543

9. Farooqi IS, Jebb SA, Langmack $G$ et al (1999) Effects of recombinant leptin therapy in a child with congenital leptin deficiency. N Engl J Med 341:879-884

10. Shimomura I, Hammer RE, Ikemoto S, Brown MS, Goldstein JL (1999) Leptin reverses insulin resistance and diabetes mellitus in mice with congenital lipodystrophy. Nature 401:73-76

11. Oral EA, Simha V, Ruiz E et al (2002) Leptin-replacement therapy for lipodystrophy. N Engl J Med 346:570-578

12. Park JY, Javor ED, Cochran EK, DePaoli AM, Gorden P (2007) Long-term efficacy of leptin replacement in patients with Dunnigan-type familial partial lipodystrophy. Metabolism 56:508-516

13. Mulligan K, Khatami H, Schwarz JM et al (2009) The effects of recombinant human leptin on visceral fat, dyslipidemia, and insulin resistance in patients with human immunodeficiency virus-associated lipoatrophy and hypoleptinemia. J Clin Endocrinol Metab 94:1137-1144

14. Chong AY, Lupsa BC, Cochran EK, Gorden P (2010) Efficacy of leptin therapy in the different forms of human lipodystrophy. Diabetologia. doi:10.1007/s00125-009-1502-9

15. Javor ED, Moran SA, Young JR et al (2004) Proteinuric nephropathy in acquired and congenital generalized lipodystrophy: baseline characteristics and course during recombinant leptin therapy. J Clin Endocrinol Metab 89:3199-3207

16. Farooqi IS, Matarese G, Lord GM et al (2002) Beneficial effects of leptin on obesity, T cell hyporesponsiveness, and neuroendocrine/ metabolic dysfunction of human congenital leptin deficiency. J Clin Invest 110:1093-1103

17. Prieur X, Tung YC, Griffin JL, Farooqi IS, O'Rahilly S, Coll AP (2008) Leptin regulates peripheral lipid metabolism primarily through central effects on food intake. Endocrinology 149:54325439

18. Leinninger GM, Jo YH, Leshan RL et al (2009) Leptin acts via leptin receptor-expressing lateral hypothalamic neurons to modulate the mesolimbic dopamine system and suppress feeding. Cell Metab 10:89-98

19. Petersen KF, Oral EA, Dufour S et al (2002) Leptin reverses insulin resistance and hepatic steatosis in patients with severe lipodystrophy. J Clin Invest 109:1345-1350

20. Robbins DC, Danforth E Jr, Horton ES, Burse RL, Goldman RF, Sims EA (1979) The effect of diet on thermogenesis in acquired lipodystrophy. Metabolism 28:908-916

21. Utzschneider KM, Trence DL (2006) Effectiveness of gastric bypass surgery in a patient with familial partial lipodystrophy. Diabetes Care 29:1380-1382 